\title{
Um modelo de condução do processo de outsourcing e um estudo de caso na indústria de processamento químico
}

\author{
Hercules B. Vernalha, MSc \\ FAAT - Faculdades Atibaia \\ Sílvio R. I. PIRes, Dr. \\ UNIMEP
}

\begin{abstract}
Resumo
Estudos tratando do processo de outsourcing em importantes setores industriais não-líderes ao redor do mundo, bem como propondo modelos práticos para a condução do processo de repasse de atividades de manufatura como um todo, e não somente no estágio de decisão, são difíceis de encontrar. Nesse contexto, este artigo procura apresentar um modelo prático para conduzir o processo de outsourcing na sua totalidade, dividindo-o em quatro estágios principais (motivação, decisão, implementação e gestão). 0 modelo foi aplicado com sucesso em um caso envolvendo duas companhias multinacionais operando no Brasil, em uma cadeia de suprimentos do setor de resinas fenólicas. Os resultados ressaltam, principalmente, a adequação do modelo proposto, no sentido de enfatizar os desafios em cada fase e as habilidades necessárias para enfrentá-los, bem como a importância da construção de parcerias baseadas na confiança e na integração por meio da tecnologia da informação.
\end{abstract}

Palavras-chave

Outsourcing, cadeia de suprimentos, resinas fenólicas.

\section{A model for guiding outsourcing process and a case study in the Chemical Processing Industry}

\begin{abstract}
Studies related to the outsourcing process in several important non-leading industries worldwide and also regarding the existence of practical models and frameworks to guide the entire process and not only the decisionmaking stage are rare to find. In this context, this article presents a practical model to guide the whole outsourcing process, divided into four main stages (motivation, decision, implementation and management). It was successfully applied in a case involving two multinational companies operating in Brazil, in a supply chain of the phenolic resin industry. The results highlighted mainly the adequacy of the proposed model, as well as the importance of constructing a partnership based on trust and integration by information technology.
\end{abstract}

Key words

Outsourcing, supply chain, phenolic resin 


\section{INTRODUĈ̣̃O}

As empresas em todo o mundo estão procurando formas não tradicionais de aprimorar suas capacitações, em virtude da forte competição e da crescente demanda por qualidade e inovação nos mercados globais. Visando reduzir custos e aumentar sua flexibilidade, os parceiros de negócios estão reforçando seus relacionamentos ao longo da cadeia de suprimentos e, dessa forma, procurando concentrar recursos em suas próprias competências essenciais.

A tecnologia da informação tem fornecido condições para o desenvolvimento de novas práticas gerenciais que dão suporte ao processo de associação com outras empresas em bem coordenadas cadeias de suprimentos, ou mesmo em empresas virtuais. Importantes iniciativas e práticas utilizadas na Gestão de Cadeias de Suprimentos (Supply Chain Management - SCM), como o VMI (Vendor Managed Inventory), o ECR (Efficient Consumer Response) e o ESI (Early Supplier Involvement), apresentam forte dependência do Intercâmbio Eletrônico de Dados (EDI), cuja implementação através da Internet conferiu maior flexibilidade e simplicidade operacional à conexão entre empresas.

$\mathrm{Na}$ última década, especialmente os setores automotivo, eletrônico e de computadores intensificaram a busca por iniciativas estratégicas, tais como o outsourcing das atividades de manufatura pertencentes às assim chamadas "áreas não-essenciais". Uma série de razões tem levado as companhias a repassar essas atividades.

Por várias décadas, a transferência de atividades limitou-se às tarefas ditas "não-produtivas" ou periféricas, sob o nome de terceirização (subcontracting), prática comum nas organizações industriais. Sua alegada motivação temse embasado, normalmente, na redução de custos, aumento de flexibilidade e intensificação da especialização em alguma área de apoio, entre outras razões. De alguma forma, incorporou-se, ao longo desses anos, a premissa de que a terceirização destina-se às atividades distantes do núcleo produtivo da empresa, tais como a segurança patrimonial, cozinha, limpeza, dentre outras, e efetiva-se através de contratos de fácil reversão. Concessões também foram feitas às áreas cuja vertiginosa demanda por renovação dos conhecimentos, como a informática, não era compatível com a estrutura da organização.

A própria legislação federal brasileira preocupou-se em restringir a terceirização à chamada "atividade-meio" do tomador (Enunciado do TST No 331 de 21 de dezembro de 1993), ainda que a diferenciação dos conceitos de atividade-meio e atividade-fim não seja absolutamente clara, além de freqüentemente passível de generalizações (APREST, 1994).
A prática do repasse ou outsourcing, por outro lado, visa à supressão de atividades tradicionalmente integrantes do processo produtivo, através de sua transferência a empresas parceiras que possam executá-las com menores custos de produção e maior velocidade de desenvolvimento de inovações (PIRES, 1998). No contexto da decisão "fazer ou comprar", ou, mais modernamente, fazer com recursos internos ou externos à empresa, o aumento da opção pelo repasse, sobretudo em determinados ramos da produção industrial, como o automotivo, tem se configurado como uma alternativa estratégica (COLLINS et al., 1997).

Na literatura em português, porém, é freqüente encontrar as práticas da terceirização e do outsourcing indistintamente referenciadas pelo vocábulo "terceirização". Neste artigo, que não pretende aprofundar a discussão que envolve essa nomenclatura, adotam-se os termos repasse ou outsourcing para referenciar a iniciativa em que se abre mão de ativos (bens), infra-estrutura, mãode-obra e competência visando à transferência de atividades-fim da empresa a fornecedores externos.

A prática do outsourcing freqüentemente resulta em mudança ou realinhamento dos agentes atuantes em determinada cadeia de suprimentos, uma vez que, ao repassar determinada atividade produtiva, não raro as empresas passam a ser abastecidas indiretamente por novos fornecedores e encaram a necessidade de implantar práticas que viabilizem o relacionamento mais estreito entre os diversos agentes dessa cadeia.

Atualmente, empresas não pertencentes aos setores considerados líderes em termos de SCM, como é o caso da Indústria de Processamento Químico (CPI), também estão procurando obter vantagens competitivas por meio do reforço de suas parcerias e da concentração do foco de sua energia gerencial em suas competências essenciais. $\mathrm{O}$ repasse das atividades de manufatura não é mais uma iniciativa rara de se encontrar entre as CPIs em muitos países, incluindo o Brasil. Porém, ainda há muito pouca literatura tratando dessas experiências.

A prática do outsourcing requer diferentes habilidades gerenciais, uma vez que integra várias funções administrativas, tais como Planejamento Estratégico, Finanças, Logística e Recursos Humanos. A contribuição das diversas funções muda ao longo do processo de implantação do outsourcing, pois cada fase apresenta características distintas.

Nesse contexto, este trabalho apresenta um modelo de quatro estágios para colaborar no estudo e na condução do processo de outsourcing. São eles: motivação, decisão, implementação e gestão.

O artigo também apresenta um caso real de repasse de atividades de manufatura na indústria de resinas fenóli- 
cas conduzida sob a perspectiva de três dos quatro estágios propostos. Os riscos, opções e soluções encontrados ao longo do processo são apontados de forma a ressaltar as principais características e desafios de cada um dos estágios.

\section{PRÁTICAS NA GESTÃO DA CADEIA DE SUPRIMENTOS}

A rápida evolução tecnológica e a crescente competição em mercados globalizados pressionam as empresas a reduzir custos, abreviar o TTM (time to market), melhorar a qualidade e agilizar a inovação de complexos produtos e serviços (FÜRST \& SCHMIDT, 2001). A solução encontrada por muitas companhias em diferentes setores produtivos para enfrentar esses desafios foi a implantação de uma bem coordenada cadeia de suprimentos. Pires (1998) vê nas práticas de SCM a busca pelos benefícios da verticalização, porém sem os prejuízos à flexibilidade que freqüentemente a acompanham.

O repasse das atividades de manufatura, por sua vez, requer um relacionamento muito próximo e harmonioso entre os parceiros, o qual é freqüentemente conseguido por meio das práticas de SCM. Entre essas práticas, o VMI (Vendor Managed Inventory) e o ESI (Early Supplier Involvement) estiveram intensamente envolvidos no processo de outsourcing do caso apresentado mais adiante neste artigo.

\section{VMI - Vendor Managed Inventory}

A Sociedade Americana de Produção e Controle de
Inventário (APICS) define VMI como "uma forma de otimizar o desempenho da cadeia de suprimentos, na qual o fornecedor tem acesso aos dados do estoque do cliente e é responsável por manter os níveis de inventário por ele requerido. O VMI é implantado através de um processo no qual o ressuprimento é feito pelo fornecedor por meio de um plano de verificações regulares dos estoques no cliente" (FLAVIN, 2002).

A julgar por essa definição, poder-se-ia acreditar que o VMI é simples de se executar sem nenhum suporte de tecnologia de informação. Waller et al. (1999) enfatizam que a implantação bem-sucedida do VMI freqüentemente depende de plataformas computacionais, tecnologia da comunicação e sistemas de identificação e rastreamento de produtos. Os autores afirmam que o EDI, sozinho, fornece poucas possibilidades de melhoria nos níveis de estocagem, mas que em conjunto com o VMI tem sido considerado muito eficaz.

O VMI controlado através de EDI se torna ainda mais confiável e fácil de implantar quando se está trabalhando com material líquido, estocado a granel. Nesse caso, um transmissor de nível do líquido instalado no tanque de armazenamento informa o MRP do fornecedor sobre quaisquer mudanças no nível dentro do tanque, em tempo real, como mostra a Figura 1.

O fornecedor pode acessar os estoques do cliente através do EDI e providenciar o enchimento do tanque de produto, assim que o ponto de reposição for alcançado, até um nível predefinido ou conforme a capacidade do tanque.

Porém, mais que acessar informações sobre o estoque,

Figura 1: VMI de produtos armazenados em tanques.

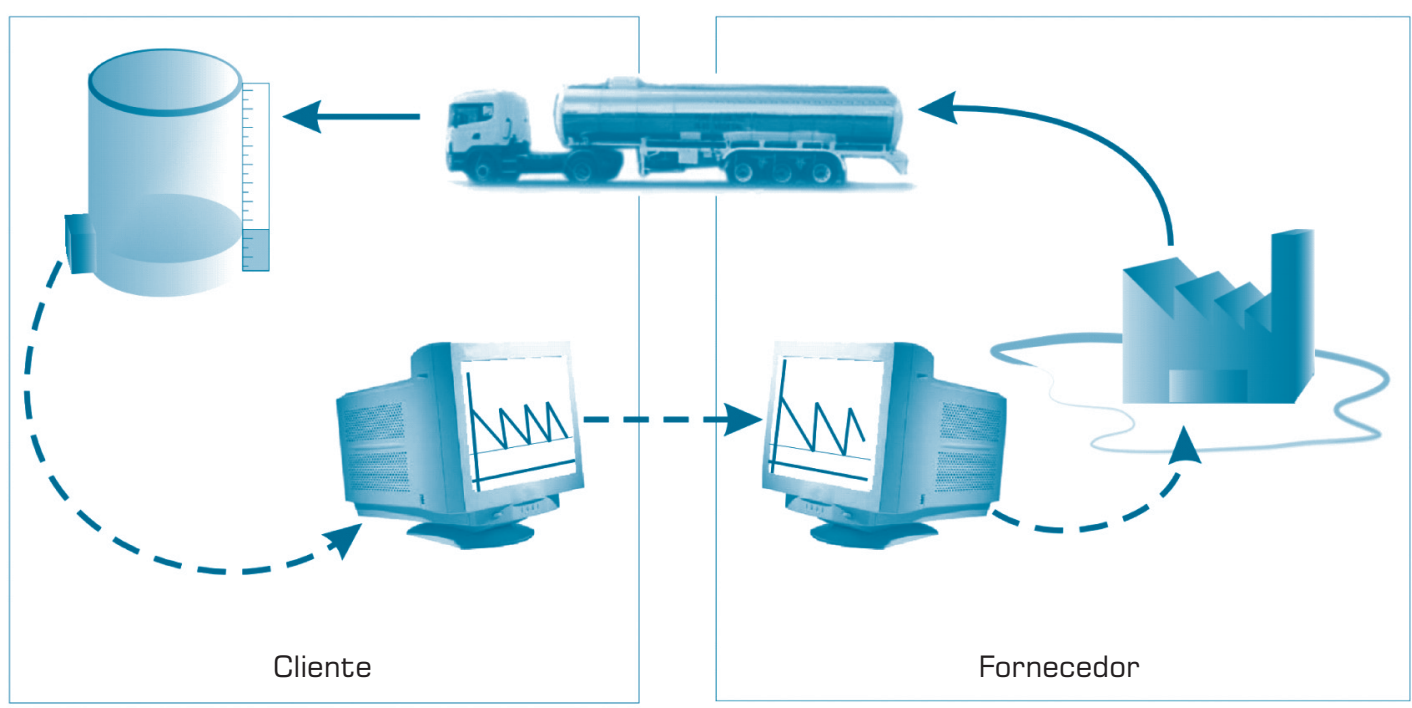


é necessário que o fornecedor receba informação sobre as tendências de mercado, de forma a assegurar uma reposição constante e eficiente. Quando os níveis mínimo, máximo e de reposição são adequadamente definidos e o fornecedor recebe informações sobre quaisquer mudanças significativas no comportamento do mercado do cliente, a prática do VMI permitirá que cliente e fornecedor consigam muitas vantagens, tais como redução de custo e maior precisão na reposição de materiais, além da simplificação e agilização na tarefa de ressuprimento.

\section{ma série de razões tem levado as companhias a repassar atividades pertencentes às chamadas "áreas não-essenciais".}

\section{ESI - Early Supplier Involvement}

Nas últimas duas décadas, o envolvimento de fornecedores no processo de desenvolvimento de novos produtos foi antecipado e aprofundado em virtude da busca pela integração das competências desses fornecedores ao projeto do produto.

Bidault et al. (1996) apontam as práticas da indústria automotiva japonesa como origem da atitude cooperativa entre clientes e fornecedores que resultou no ESI. Eles afirmam que certos fatores que proporcionam a adoção do ESI, como a competição e a cultura do país, são externos à organização, enquanto outros estão relacionados à sua estratégia interna ou a questões operacionais, como o nível de integração e globalização.

O modelo proposto por Calvi et al. (2001) apresenta uma matriz baseada na autonomia do fornecedor no desenvolvimento do projeto e no risco desse desenvolvimento. Eles reconhecem cinco tipos possíveis de envolvimento do fornecedor, desde o relacionamento do tipo "contratação clássica" até o co-desenvolvimento crítico. Durante o processo de outsourcing das atividades de manufatura, o estreito relacionamento entre cliente e fornecedor cria o ambiente adequado para a melhoria do produto ou até para o co-desenvolvimento de novos produtos.

\section{Outsourcing das atividades de manufatura}

Apesar do ambiente de intensas mudanças exercer crescente pressão por melhoria de desempenho e impor restrições, ele oferece, ao mesmo tempo, oportunidades de exploração dos recursos de forma a atender os requisitos do negócio (DEKKERS, 2000). O repasse (outsourcing) das atividades de manufatura é uma prática crescente entre as empresas que buscam, principalmente, voltar suas energias para a realização de suas atividades essenciais e consideradas não passíveis de serem repassadas a fornecedores externos. Na busca por fornecedores com classe mundial, o impacto do outsourcing das atividades produtivas via de regra transcende os parceiros da iniciativa e resulta em um realinhamento dos agentes da cadeia de suprimento, com a entrada de novos fornecedores e clientes.

Ehie (2001) afirma que o outsourcing das atividades de manufatura está ligado ao processo de determinação de quais dentre essas atividades deveriam ser transferidas a um fornecedor externo. A essência do outsourcing é o uso das instalações produtivas de outras empresas ao invés de utilizar recursos existentes na companhia ou de fazer novos investimentos na estrutura produtiva. É uma iniciativa complexa que envolve diferentes funções gerenciais, desde a fase de motivação até o gerenciamento do processo plenamente implementado.

Nesse contexto, este artigo propõe um modelo de quatro estágios para conduzir o processo de outsourcing, visando à facilitação da identificação de características, riscos e desafios presentes em cada um deles. A Figura 2 mostra a seqüência desses estágios, os quais são descritos abaixo.

(a) Motivação: A definição das razões para o outsourcing freqüentemente passa por um planejamento estratégico ou tático que pode afetar profundamente o desempenho da empresa. Quando uma oportunidade para o outsour-

Figura 2: Divisão do processo de outsourcing em quatro estágios.

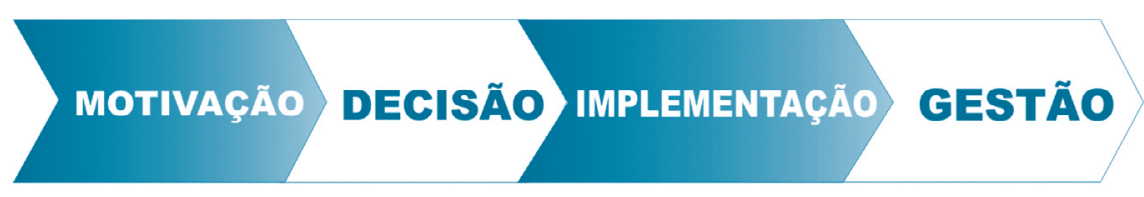


cing é corretamente identificada, ela permite à organização focar seus esforços em suas próprias competências essenciais, proporcionando, dessa forma, mais valor a seus produtos e a oportunidade de reduzir seus custos. Por outro lado, o repasse de uma atividade estrategicamente ou criticamente importante pode colocar a empresa em sérias dificuldades.

Ehie (2001) realizou uma pesquisa na qual se questionaram 108 empresas de manufatura americanas sobre suas razões para a prática do outsourcing. Os resultados estão ilustrados na Figura 3.

Quinn \& Hilmer (1994) trabalharam em um modelo para determinar se uma atividade não essencial deve ou não ser repassada, através de três questões básicas:

1- Qual o potencial para se obter uma vantagem competitiva nessa atividade, levando-se em consideração os custos da transação?

2- Qual a vulnerabilidade potencial que poderia surgir a partir de uma falha de mercado, caso fosse feito o out sourcing da atividade?

3- O que pode ser feito para aliviar a vulnerabilidade, através da estruturação de acordos com os fornecedores para garantir os controles apropriados e ainda prover a necessária flexibilidade na demanda?

Neste ponto, Quinn \& Hilmer (1994) identificam dois fatores que afetam as decisões pelo outsourcing de atividades de manufatura: o grau estratégico de vulnerabilidade (risco do negócio) e o potencial para vantagem competitiva. Atividades que fornecem pouca vantagem competitiva e baixa vulnerabilidade de fornecimento deveriam ser repassadas; já aquelas que fornecem alta vantagem competitiva e expõem a companhia a um alto grau de risco do negócio, em função da vulnerabilidade do fornecedor, deveriam ser produzidas "em casa". Entre esses dois extremos, há um continuum de atividades demandando diferentes graus de controle e flexibilidade estratégica.

(b) Decisão: Importantes decisões que envolvem aspectos estratégicos, técnicos, financeiros e logísticos são tomadas neste estágio do processo. Tendo em vista ser o outsourcing um acordo de longo prazo, a escolha de um parceiro sólido, capacitado e confiável é um passo decisivo em direção a uma parceria de sucesso.

Figura 3: Porcentagem de respondentes indicando razões para a opção pelo outsourcing.

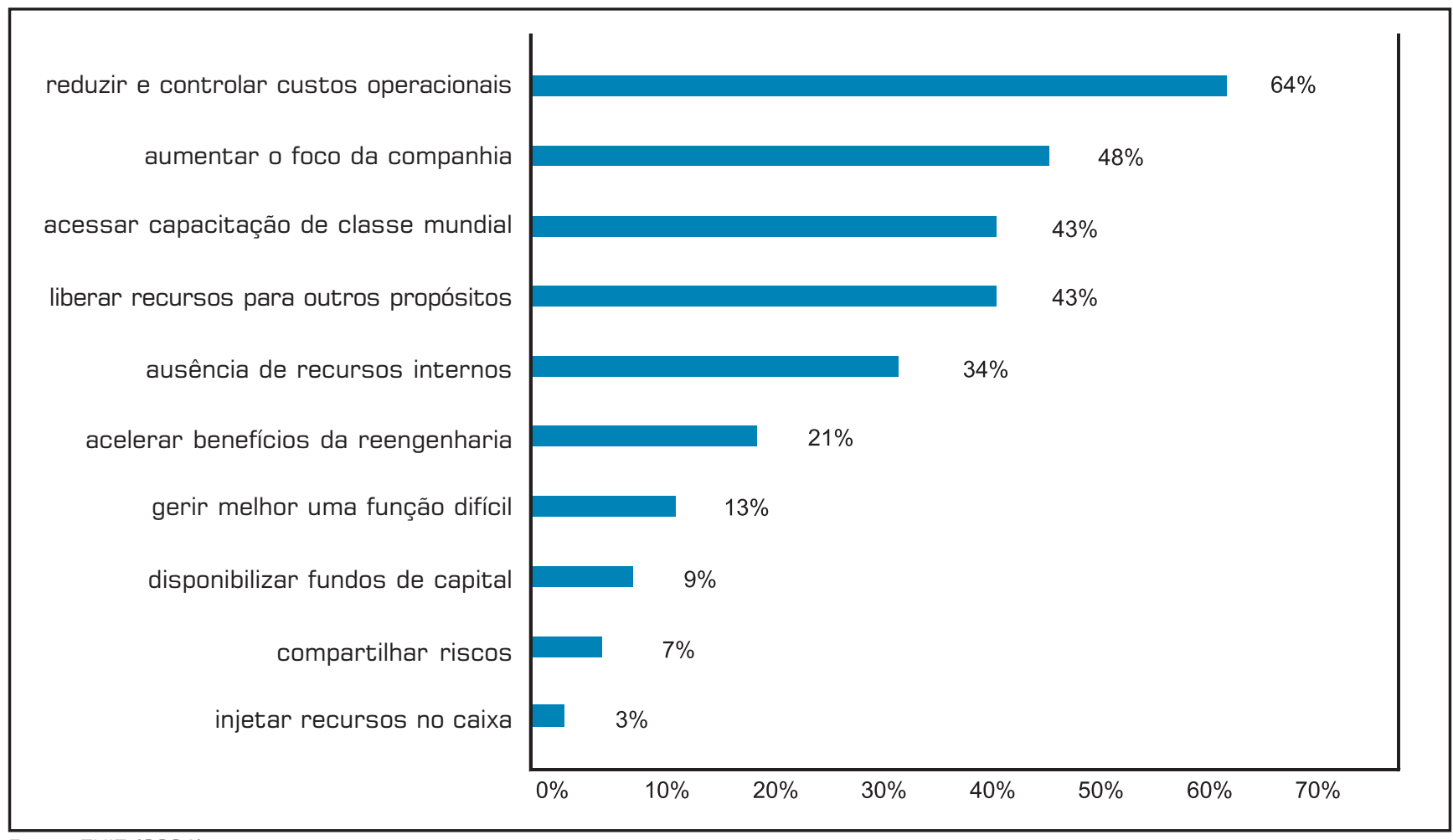

Fonte: EHIE (2001) 
Brueck (1995) propõe quatro requisitos-chave para a escolha do fornecedor:

- Desenvolvimento de know-how;

- Adequada capacitação de manufatura e custo da estrutura;

- Estabilidade financeira enquanto parceiro no negócio;

- Lealdade.

Monczka (1998) aponta para a importância do estudo detalhado dos custos envolvidos na operação de outsourcing, em comparação com os custos da manufatura "em casa". Ele lista os diversos elementos que compõem os custos variáveis, os custos diversos de fabricação e os custos operacionais da manufatura. $\mathrm{O}$ autor alerta para o risco de que diversos elementos de custos de overhead não sejam computados, em função da tendência dos gerentes de produção de escondê-los, visando à continuidade da fabricação em suas próprias plantas.

Com relação aos limites e interfaces que irão regrar o relacionamento entre cliente e fornecedor, Brueck (1995) acredita que a definição correta do sistema de informação seja um fator-chave em todo processo de outsourcing. Ele aponta duas questões predominantes: qual interface deveria ser escolhida e quais deveriam ser as dimensões do sistema de outsourcing.

O próprio autor sugere que a solução para essas dúvidas está em manter-se a simplicidade. A interface com o fornecedor deveria ser projetada de forma que a clara demarcação do limites do sistema viesse a simplificar a operação de ambas as companhias e, ao mesmo tempo, abrisse possibilidades para melhorias de ordem técnica.

Outra importante escolha está relacionada ao tipo de contrato de outsourcing a ser adotado. Contratos do tipo "pacote fechado" (lumpsum) permitem ao consumidor conhecer previamente os custos totais, mas, por outro lado, demandam mais tempo dedicado ao desenvolvimento de uma descrição muito completa e precisa do propósito do contrato. Por sua vez, contratos do tipo "por medição" (reimbursable) permitem que se mude o escopo do trabalho, mas também aumentam os riscos de estouro nos custos e nos prazos planejados.

(c) Implementação: Esta fase do processo de outsourcing requer que se desaprendam e reaprendam diversos conceitos sobre gestão de recursos. As empresas fornecedoras e clientes terão que trabalhar juntos para enfrentar novos desafios no planejamento da produção, logística de matérias primas e produtos acabados e controle de custos. Motivar os funcionários a compartilhar informações e habilidades é também um importante passo neste estágio. A tecnologia de informação é uma ferramenta essencial para dar suporte ao desempenho das novas atividades, ajudando na integração entre fornecedor e cliente.
ROTHERY \& ROBERTSON (1995) alertam para a variada gama de reações negativas que o processo de outsourcing pode despertar no pessoal mais envolvido com funções afetadas, em virtude do medo e da rejeição às mudanças. Entre elas estão a desconfiança, o estresse, a agressividade, o desânimo, o isolamento e até a sabotagem. Não obstante, os autores apontam a ocorrência de reações individuais positivas à mudança, do tipo "vamos experimentar e ver", que acabam resultando na percepção de que nova situação pode ser compreendida e manejada com sucesso.

Como sugestões para facilitar a superação das dificuldades que podem advir das mudanças, os autores sugerem, dentre outras, a intensa comunicação com o grupo e também com os indivíduos em particular, incluindo o feedback do desempenho e a emissão de mensagens claras sobre a segurança do emprego.

Tratando dos riscos de implantação do processo de outsourcing, Monczka (1998) aponta a existência de diversos fatores, tais como:

- Problemas com a capacitação, tais como qualidade, tempo de ciclo, tecnologia, e custos;

- Itens ligados ao gerenciamento, como objetivos, priorização de tarefas, desempenho;

- Desvios de ética envolvendo propriedade da informação e exagerada dependência do fornecedor;

- Problemas relativos ao mercado, tais quais a criação inadvertida de um concorrente e a transferência de knowhow para a concorrência.

(d) Gestão: A administração do processo de outsourcing no longo prazo, por sua vez, deverá assegurar a melhoria contínua dos benefícios da iniciativa de repasse, através da freqüente avaliação do processo e também da pesquisa de novas formas de mantê-lo interessante e lucrativo.

Harbison \& Parker (1998) apresentaram uma série de fatores, os quais são apontados como melhores práticas para sucesso de parcerias com fornecedores. São eles:

- Criação de uma estrutura organizacional flexível e enxuta;

- Basear os processos e a estrutura da parceria na estratégia e nas necessidades da mesma e não nas "particularidades" dos parceiros;

- Acompanhar a reação dos concorrentes à parceria;

- Preparar e revisar periodicamente detalhados cronogramas, entre outras ferramentas de acompanhamento;

- Confiar na comunicação aberta como forma de obter a flexibilidade na solução das questões que apareçam;

- Definir, desde o início, os papéis do gerenciamento;

- Fornecer aos gerentes a força necessária para atingir os objetivos;

- Tornar acessíveis aos participantes, em tempo real, as lições aprendidas com a parceria. 
Com relação aos novos modelos de gerenciamento a serem adotados ao longo dos processos de outsourcing, Quinn \& Hilmer (1994) apontam a necessidade de efetuarem-se ajustes em três áreas, a saber:

1- desenvolver gerenciamento de compras e contratos muito mais profissional e altamente treinado;

2- aprimorar intensamente o sistema de informação logística; 3- aprimorar o gerenciamento do conhecimento.

Novos modelos de gerenciamento deverão ser desenvolvidos ao longo do tempo em que se pratica o outsourcing, para assegurar a gestão eficiente da informação envolvendo compras, contratos e operações logísticas. A ação conjunta das equipes técnicas de ambos os parceiros no sentido do aprimoramento e criação de produtos deve ser intensamente estimulada.

\section{UM CASO DE OUTSOURCING NA INDÚSTRIA DE RESINA FENÓLICA}

Na seqüência deste artigo, será apresentado o estudo de um caso de outsourcing realizado na indústria de fabricação de resinas fenólicas operando no Brasil. As empresas envolvidas no caso estudado estão apresentadas sob nomes fictícios.

Trata-se de um processo de repasse das atividades de manufatura de toda uma linha de resinas fenólicas de uma empresa de processamento químico, afiliada da Alffa Chemical norte-americana, para uma concorrente, afiliada de outra multinacional do ramo de resinas fenólicas, a Betta International. A iniciativa visou ao encerramento das atividades de uma planta da Alffa na cidade de Cotia. Nessa planta, além de manufaturar, embalar, armazenar e distribuir o produto, a Alffa fabricava também uma das principais matérias-primas da resina, o formaldeído.

$\mathrm{Na}$ condição de gerente industrial de uma das empresas envolvidas no processo de outsourcing investigado, a Betta Brasil, o autor deste trabalho teve condição privilegiada para contatar cada um dos protagonistas do processo, bem como coletar, classificar e reconfirmar uma farta coleção de dados relacionados ao caso em estudo. Por outro lado, em virtude dessa mesma condição, o autor interferiu no processo, visando ao aprimoramento de seus resultados, muitas vezes utilizando-se dos próprios conhecimentos teóricos adquiridos para viabilização do desenvolvimento da pesquisa.

Fica claro que a metodologia utilizada na investigação foi do tipo pesquisa-ação. Nessa modalidade metodoló- gica oriunda das ciências sociais, o pesquisador não só participa do fenômeno observado, mas contribui para o seu planejamento com vistas à resolução de problemas ou transformação de situações.

O modelo proposto neste artigo, portanto, foi desenvolvido paralelamente ao desenrolar do processo de outsourcing descrito a seguir, de tal forma que a composição do modelo serviu-se da observação do caso bem como o processo foi muitas vezes orientado pelo conhecimento levantado na pesquisa que levou ao estabelecimento do modelo.

O estudo de caso apresenta as três primeiras etapas do processo de outsourcing analisado. Em virtude do prazo dedicado a esse estudo, não houve tempo hábil para colher dados que permitissem identificar os aspectos típicos da fase de gestão, que demandariam acompanhar o amadurecimento da prática do outsourcing.

Uma vez que a Betta Brasil não costumava fornecer usualmente o serviço de manufatura de produtos a terceiros, muito menos nos volumes envolvidos neste caso, o processo de outsourcing pesquisado foi precedido pelo exercício do planejamento estratégico em duas diferentes dimensões e em momentos distintos: a dimensão do cliente e a dimensão do fornecedor.

\section{N outsourcing abre-se mão de ativos, infra-estrutura, mão-de-obra e competência ao repassar atividades ligadas diretamente ao "core business" para fornecedores.}

A primeira delas teve lugar na Alffa Química, quando profundas reestruturações na organização da empresa culminaram na opção pelo repasse da manufatura das resinas de fricção, em termos que podem ser resumidos da seguinte forma:

- O fornecedor fabricaria as resinas de fricção utilizando as formulações da Alffa;

- O fornecedor embalaria as resinas em sacarias contendo o logotipo da Alffa;

- A Alffa forneceria a matéria-prima e providenciaria a distribuição do produto;

- A Alffa encerraria as atividades da planta onde tradicionalmente fabricava as resinas de fricção.

A segunda deu-se na Betta Brasil, quando, a partir da formalização do interesse da antiga concorrente em transferir a ela toda sua produção dessas resinas, optou por assumir o repasse, que significaria, à época, um 
acréscimo de $50 \%$ na sua produção bruta.

Por esse motivo, nas fases de motivação e decisão, decidiu-se apresentar os fatores apurados ao longo do trabalho de pesquisa, divididos em duas partes, como se pode constatar na Figura 4.

\section{A indústria de resina fenólica no brasil}

A resina fenólica é classificada como um polímero obtido a partir da reação de condensação. Nesse tipo de reação, o polímero cresce a partir da combinação de duas grandes moléculas e da liberação de uma terceira pequena molécula, normalmente água. Dependendo da formulação do produto, uma novolaca ou um resol são produzidos.

As novolacas são projetadas para incorporar um agente de cura, tal como a hexametilenotetramina, e são também chamadas de duplo-estágio, enquanto os resóis não necessitam agente de cura e, em virtude de sua característica de componente único, são também chamados de estágio-único.

Os produtos-alvo do contrato de outsourcing estudado neste trabalho são resinas fenólicas do tipo novolaca, utilizadas na confecção de materiais de Fricção e Abrasivos, por vezes tratadas somente como resinas de fricção.

$\mathrm{O}$ parque industrial dedicado à fabricação de resinas fenólicas no Brasil tem tradicionalmente se caracteriza- do por apresentar capacidade ociosa em relação à demanda de mercado. A situação fica mais evidente quando se consideram as resinas menos diferenciadas; essas resinas são tratadas praticamente como commodities. Entre elas, estão as resinas de fricção.

Por essa razão, o mercado brasileiro de resinas fenólicas tem sido considerado como altamente competitivo. A satisfatória resposta às demandas dos clientes, o correto cumprimento dos prazos de entrega, a alta flexibilidade no aspecto quantidade e um excelente atendimento personalizado são vantagens competitivas ganhadoras de pedido nesse mercado onde o preço é um quesito qualificador, seguindo a classificação de Hill (1993). Inovações, em diversas linhas de produto, não se verificam há anos.

Entre os desafios enfrentados pela indústria de manufatura de resinas fenólicas no Brasil, alguns dos mais significativos estão ligados ao volume de produção. São eles:

- Custo da Matéria-Prima: o Fenol, principal componente dessas resinas, é fabricado no Brasil pela Rhodia Brasil S.A., afiliada do Groupe Rhodia francês, que tem grande capacidade de fabricação e forte poder de negociação na comercialização desse produto no País. O preço do fenol praticado no Brasil apresenta-se, freqüentemente, majorado em relação ao fornecido no mercado internacional. Importar o produto através das inseguras estruturas portuárias brasileiras, porém, pode significar risco de desabaste-

Figura 4: Representação esquemática das etapas do processo de outsourcing estudado.

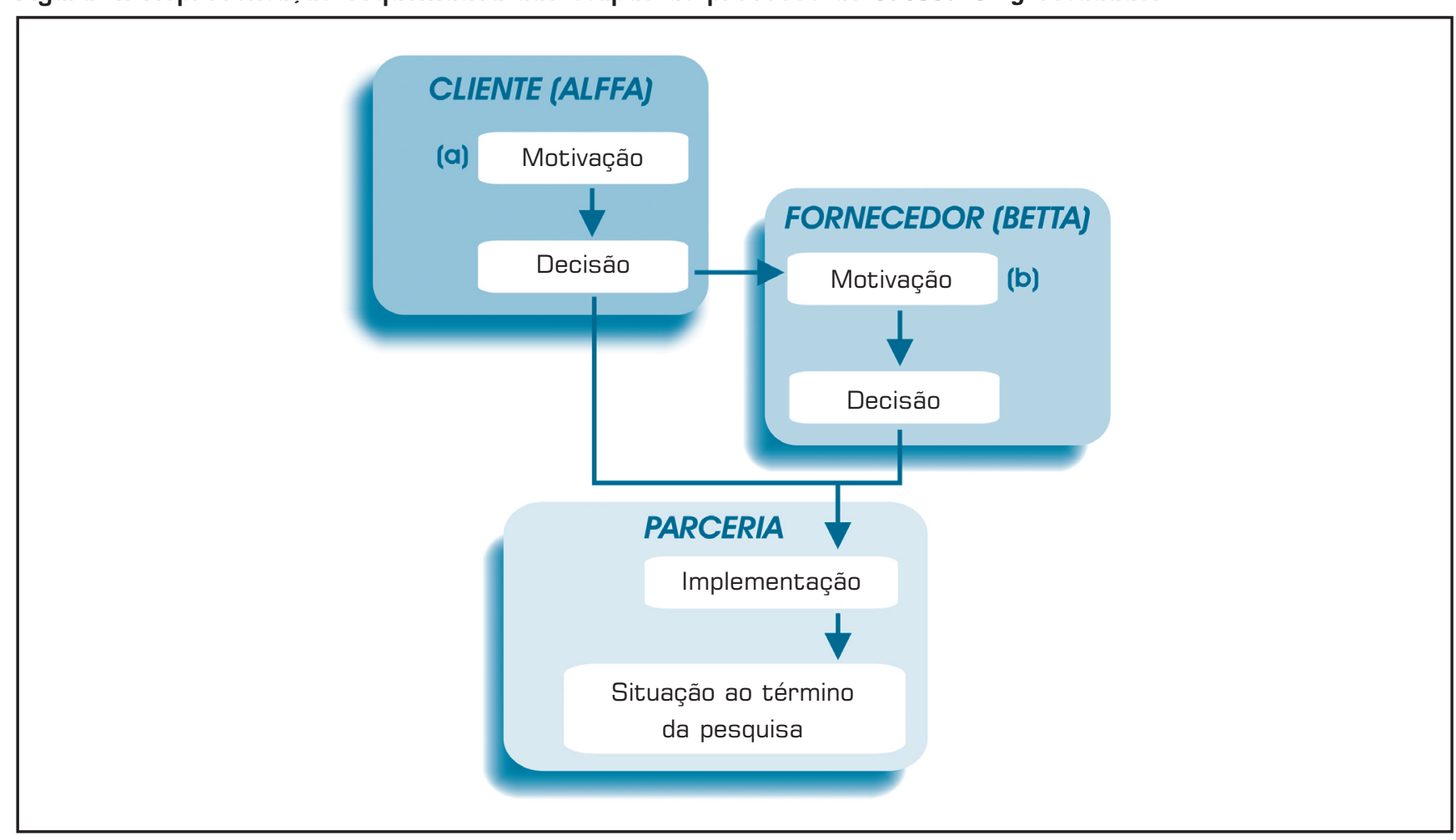


cimento e prejuízo. Só se justifica em caso de volumes realmente significativos.

- Tratamento de Efluentes: os resíduos líquidos resultantes do processo de fabricação de resinas fenólicas apresentam teores de fenol e de formaldeído em sua composição. A presença simultânea desses dois componentes torna bastante complexo seu tratamento pela via biológica, pois os microorganismos que degradam um dos compostos são, normalmente, incompatíveis com o outro. Incineradores demandam sofisticada instrumentação para monitorar o processo de queima a temperaturas superiores a $1.200^{\circ} \mathrm{C}$. Em conseqüência disso, os investimentos no tratamento de efluentes químicos dessas plantas são consideráveis e passam a viabilizar-se somente a partir de uma determinada escala de produção.

- Tecnologia de Produção em Massa: em alguns países mais industrializados, a produção de resinas fenólicas através de lotes (batches) foi substituída pela produção contínua. Essa tecnologia aumenta muito a capacidade produtiva, barateando o custo unitário de produção. Porém, ela demanda investimento de capital em equipamentos produtivos e automação, que só se justifica em caso de alta demanda de mercado.

Portanto, vários desafios para maximização da lucratividade ou, em alguns casos, da redução das perdas da indústria de resinas fenólicas estão ligados ao aumento do volume de produção, o que equivale a dizer, tendo em vista a limitação da demanda local, redução da sua partição entre muitos competidores. Ao longo dos últimos anos cresceu a percepção de que esse retalhamento é pernicioso para os resultados das empresas. A partir daí, iniciaram-se os primeiros movimentos no sentido da reestruturação do setor.

\section{A Betta Brasil Ltda.}

Desde meados dos anos de 80, a Betta Brasil Ltda. (Betta) tem investido em uma política de constante modernização de suas instalações industriais e nas práticas de lean production, desenvolvendo assim um diferencial competitivo no âmbito das empresas de manufatura de resinas. Ela foi uma das pioneiras na instalação de itens tais como esteiras de resfriamento do filme de resina do tipo flaker belt, controle de reatores e utilidades através de PLC e sistema de entamboramento automático de resinas líquidas.

Além disso, a Betta foi uma das primeiras afiliadas do grupo a certificar-se conforme normas internacionais de qualidade. Este perfil de alta competência de manufatura traduziu-se na intensificação dos negócios com resinas e esmaltes diferenciados, mas não resultou na ampliação do volume de vendas das resinas menos elaboradas. Por esse motivo, a empresa terminou a década de 1990 sofrendo o impacto dos altos custos de matéria-prima, sobretudo o fenol, e das significativas despesas com tratamento de efluentes fora de sua planta.

No caso específico das resinas de fricção, essa situação traduziu-se no crescente desinteresse da Betta em produzi-las, em virtude dos preços reduzidos, da alta taxa de geração de efluentes resultantes do processo produtivo e do alto custo de manufatura, por serem produzidas com um segundo estágio (a moagem) no qual incorporam um agente de cura. No início do ano 2000, o volume de resinas de fricção manufaturado pela empresa representava algo em torno de $6 \%$ de sua produção total.

\section{VMI controlado através de EDI se torna ainda mais confiável e fácil de tantar quando se está trabalhando com material líquido, estocado a granel.}

\section{A Alffa Química}

Em meados dos anos 90, a Alffa Química decidiu reestruturar seus negócios no Brasil. A empresa definiu-se pela cisão em duas outras organizações independentes, ambas sob o controle da Alffa Chemical Inc.: a Alffa Adesivos Ind. e Com. Ltda. e a Alffa Química Ind. e Com. Ltda. Entre outros motivos, a divisão visava intensificar o foco de cada uma das empresas em um portfolio de produtos mais similares.

A Alffa Química modernizou suas instalações no sul do País e ali concentrou investimentos, implantando a maior fábrica de formaldeído da América Latina e produzindo resinas para o setor madeireiro e moveleiro. Porém, a planta de produção de resina novolaca para fricção, em Cotia, não acompanhou essa evolução e apresentava, por ocasião do reposicionamento estratégico da companhia, equipamentos com muitos anos de uso e desatualizados: reatores sem comando eletrônico, ausência de flaker-belt (esteira para fabricação de resina no formato de escamas) e ensacadeira para sacos costurados.

Então, como parte da profunda reestruturação estratégica da companhia, decidiu-se pela interrupção da produção de resinas de fricção na planta de Cotia, e por seu repasse para outra companhia.

\section{A motivação para a prática do outsourcing}

\section{(a) Na Alffa Química}

Abrir mão da fabricação própria de resinas fenólicas 
significou, para a Alffa, evitar investimentos inadiáveis em equipamentos e tecnologia que lhe permitissem permanecer competitiva e lucrativa no segmento de resinas de fricção. Cruzando a baixa competitividade na capacitação com sua baixa importância estratégica, concluiu-se que o outsourcing da fabricação das novolacas era recomendável.

Adicionalmente, a possibilidade de reduzir custos com mão-de-obra, matéria-prima, utilidades e tratamento de efluentes, tendo em vista a economia de escala que representaria sua produção conjunta com a de um outro fabricante do produto, pareceu muito interessante. volume de produção bruta.

- A possibilidade de adquirir alguns equipamentos a preços especiais da planta de Cotia da Alffa, limitada a alguns itens de utilidades (compressores, coolers e motores elétricos);

- A certeza de que, recusada a proposta, o negócio seria perdido para um concorrente.

Os fatores que pesavam contra a aceitação da proposta de outsourcing eram a ocupação da capacidade produtiva com um produto de baixa lucratividade (commodity), inibindo a aceitação futura de possíveis negócios mais lucrativos e o aumento de $50 \%$ na previsão de gastos com ativo-fixo para o ano de 2001, em função da adaptação e ampliação necessárias nas instalações da planta.

\section{O processo de decisão}

A Alffa Química decidiu-se em favor planejamento estratégico em duas diferentes dimensões e em momentos distintos. ceira para outsourcing de suas resinas de fricção, no final de 2000. No ano de 1998, a direção da Alffa visitara a planta

Sem dúvida, também pesou a favor da decisão a possibilidade de sensível redução nos custos fixos resultante do fechamento da planta de Cotia.

Por outro lado, o risco de que o negócio passasse definitivamente para o controle do fornecedor, em virtude, dentre outras razões, da pouca sofisticação ou inovação tecnológica existente nesse tipo de produto, foi o fator de maior preocupação em torno da decisão pelo outsourcing das resinas de fricção naquele momento. Cabe lembrar que, apesar de tudo, o faturamento com a resina era bastante significativo e sustentado pelo maior diferencial competitivo da Alffa nesse segmento: a estrutura de marketing e vendas da companhia.

\section{(в) Na Betta Brasil Ltda.}

Ao final de 1999, a direção da Betta Brasil elencou uma série de fatores estratégicos pró e contra a aceitação da proposta de assumir a fabricação da linha de resinas de fricção da Alffa Química. A favor do acordo, pesaram os seguintes fatores:

- A redução nos gastos com matéria-prima, pois, passando a manufaturar a maior fatia do mercado brasileiro de resina em pó e aproveitando-se do know-how de importação da Alffa, a empresa conseguiria adquirir fenol importado ou pelo menos melhores preços com a Rhodia.

- Redução de custos de produção com melhores negociações de preço de diversos itens, tais como tratamento de efluentes, nitrogênio de refrigeração para moagem, sacaria, etc., resultantes do aumento no volume.

- Diluição de custos fixos com o aumento de 50\% do de Atibaia pela primeira vez, com a justificativa de "possíveis negócios futuros". Nessa ocasião, manifestaram-se favoravelmente impressionados com os equipamentos e as instalações.

De fato, as condições técnicas de processo apresentadas pela planta da Betta poderiam conferir a seu produto diversos avanços em termos de qualidade, apresentação e produtividade:

- A existência de um flaker-belt permitiria à Alffa fornecer a parte não pulverizada da sua linha de resina na apresentação em escamas;

- O controle lógico programável dos reatores possibilitaria alcançar maior qualidade e estabilidade no produto, além de maior produtividade no processo de fabricação.

- A embalagem do produto moído em ensacadeira pneumática, utilizando sacos valvulados multifoliados e protegidos contra umidade, atenderia uma antiga demanda do mercado, e poderia inclusive favorecer o desenvolvimento de novos clientes e a participação da empresa em outras cadeias de suprimentos.

Por ocasião da efetivação do contrato com a Betta, os dirigentes da planta de Cotia da Alffa confirmaram a modernidade das instalações e as condições gerais da planta de Atibaia como um dos motivos de sua escolha, em detrimento de outras empresas analisadas.

No final de 1999, porém, a Betta informou aos negociadores da Alffa que estava em adiantado processo de fusão com a Deltta Resinas, cujo controle acionário seria adquirido pela Betta International. Esse fator inesperado 
configurou-se em um grande empecilho a ser vencido. A preocupação da Alffa residia, basicamente, em dois fatores:

- o risco de perda imediata da tecnologia de produto para um forte concorrente. Se, por um lado, a inovação dessa tecnologia era bastante baixa, a perspectiva de que todas as fórmulas passassem de uma só vez às mãos de um competidor agressivo como a Deltta Resinas era um fator de muito desconforto.

- A competição entre a Alffa e a Deltta no mercado das resinas sintéticas foi sempre intensa. Os gerentes de vendas da Alffa manifestaram desconforto com a hipótese de um relacionamento mais estreito com o concorrente nacional, que consideravam agressivo.

Foram também dois os fatores que influenciaram a direção da Alffa Química no sentido de superar o temor e consumar a negociação:

- O posicionamento da Betta no mercado de resinas era visto como altamente ético e as equipes de vendas de Betta e Alffa possuíam relacionamento cordial;

- A Betta é afiliada de uma companhia norte-americana. A Alffa sentiu-se segura em negociar com uma empresa com origem e, portanto, práticas e cultura semelhantes às suas. Além disso, quando foram acionadas, as matrizes de ambas as companhias reportaram o ótimo relacionamento que sempre existiu entre seus dirigentes.

Conclui-se que a afinidade existente nas culturas organizacionais de ambas as empresas foi definitiva para a efetivação do negócio.

Tratando agora do processo de decisão da Betta pelo aceite em assumir o repasse, convém relatar que, tendo em vista a possibilidade de sucesso da negociação entre as duas empresas, mais uma divisão da Alffa, responsável pela fabricação de outra linha de resinas, interessou-se por repassar a manufatura de seus produtos para a Betta.

Pouco tempo depois dessa oferta, uma outra grande multinacional do ramo químico procurou a gerência da Betta pretendendo fazer o outsourcing de uma resina da sua linha de poliésteres, em condições bastante razoáveis. Esse interesse pela manufatura de produtos na planta da Betta em Atibaia despertou no gerenciamento da empresa a atenção para a possibilidade de focar a manufatura como competência essencial.

O contrato de outsourcing entre a Alffa Química e a Betta foi definitivamente assinado em fevereiro de 2001. Seu conteúdo previa, entre outras cláusulas:

- Vigência de cinco anos;

- Pagamento por medição (em toneladas de produto);

- Fabricação rigorosamente de acordo com as especificações técnicas da Alffa;
- Todas as matérias-primas fornecidas pela Alffa;

- Embalagem e rotulagem no padrão da Alffa;

- Prazo de entrega de duas semanas depois de recebida a ordem de compra;

- Local de retirada nas dependências da Betta;

- Previsão de Demanda com antecedência de 90 dias;

- Confidencialidade das informações provindas da Alffa. como altamente competitivo.

\section{A implementação}

A fase de implementação do processo de outsourcing pesquisado apresentou os seguintes aspectos relevantes:

- O acordo final atrasou três meses, em função das definições financeiras e dos acertos a respeito do sigilo das informações;

- Apesar do atraso no contrato, a Alffa cumpriu o cronograma de interrupção da fabricação na planta de Cotia, visando obter a redução de custos, que era uma das principais motivações da iniciativa de repasse. A parada deu-se no final de fevereiro de 2001;

- O trâmite para liberação dos gastos com ativo-fixo pela matriz da Betta foi demorado e a instalação dos equipamentos necessários à produção das resinas repassadas foi retardada. Isso afetou de alguma forma a produtividade e a qualidade da manufatura;

- Houve algumas dificuldades para contabilização da matéria-prima consumida e do material produzido, em função de diferentes metodologias para estimativa de perdas ao longo da manufatura;

- A logística relativa à entrega de matérias-primas apresentou problemas:

o Algumas matérias-primas não foram entregues a tempo para início da manufatura. A Betta utilizou seu próprio material.

o Algumas matérias-primas entregues em sacaria não apresentavam características adequadas para repor as utilizadas pela Betta;

o Algumas matérias-prima entregues a granel apresentavam características, tais como cor, pureza ou concentração, diferentes das utilizadas na Betta e, portanto, não puderam ser armazenadas nos mesmos tanques, causando gastos adicionais.

o Algumas importantes matérias-primas líquidas, na planta de Atibaia, são armazenadas em tanques de estocagem. Seu reabastecimento é feito através de EDI com os fornecedores. Uma vez que os ERPs de Alffa e 
Betta não foram convenientemente programados para a interconexão eletrônica, a gestão do reabastecimento de matérias-primas tornou-se mais cara e complexa e a prática do VMI foi temporariamente inviabilizada. Em conseqüência, ocorreram episódios de excesso de abastecimento e também de falta de material, acarretando algum acréscimo de custos.

- Conciliar a programação de Alffa e Betta na fábrica de Atibaia constituiu-se em um dos mais importantes desafios para as equipes de gerenciamento do processo de outsourcing. A priorização dos lotes a serem produzidos, por vezes, mostrou-se confusa. Algumas mudanças no plano de produção foram pedidas com menos de três dias de antecedência. Informações deficientes sobre as vendas da Alffa e a falta de acesso ao Programa Mestre de Produção (MPS) da Betta foram reconhecidas como os maiores problemas para se atingir um planejamento da produção consistente e realista.

- Houve problemas também com a entrega dos produtos acabados:

o A sacaria não foi pedida / entregue a tempo em virtude do atraso no fechamento do contrato. Inicialmente, foram necessárias improvisações na embalagem e identificação dos produtos;

o As dimensões da sacaria utilizada na Betta não eram compatíveis com o espaço disponível nos caminhões da transportadora contratada pela Alffa.

- Notaram-se dificuldades no diálogo entre os parceiros com relação às análises físico-químicas a serem efetuadas. De maneira geral, as mesmas propriedades eram investigadas, porém através de ensaios diferentes. Apesar do bom relacionamento das equipes gerenciais que traba- produtos existentes, bem como a alta viabilidade do desenvolvimento conjunto de novos produtos.

\section{Situação ao término da pesquisa}

No segundo semestre de 2001, seis meses depois de firmado o contrato de outsourcing entre Alffa e Betta, os seguintes resultados foram verificados:

- A produção de resina de fricção em Cotia estava definitivamente encerrada;

- O manuseio das formulações e outros dados vindos da Alffa ficaram absolutamente restritos ao pessoal da Betta;

- O volume de manufatura na Betta atingiu somente $70 \%$ do inicialmente planejado para o mês;

- O investimento em ativo-fixo superou o orçado em $15 \%$ até a data. Em torno de $60 \%$ das atividades do projeto de instalações de equipamentos estavam concluídas;

- Houve duas reclamações de clientes com relação a problemas (pouco graves) de qualidade com os produtos, número considerado baixo em comparação com o histórico dessas resinas;

- Melhores preços de tratamento da água efluente do processo já estavam em vigor há três meses;

- As negociações sobre o preço de fenol com a Rhodia ainda estavam em andamento;

- A programação dos lotes de produção não havia alcançado a estabilidade, ou seja, ainda não era possível atingir o número usual de dias de plano congelado.

\section{CONSIDERAC̣ÕES FINAIS}

Baseado nos dados obtidos a partir do estudo de caso realizado foi possível observar que a divisão em etapas do modelo proposto é aplicável a um caso de outsourcing entre empresas produtoras de resinas fenólicas, ainda que, com respeito às três primeiras fases propostas no modelo, os limites (início e término) de cada uma delas pareceram não ser rigidamente definidos, podendo haver interpenetração entre fases subseqüentes, como indicam os seguintes aspectos:

lharam para o sucesso da iniciativa do outsourcing, demorou aproximadamente dois meses até que o pessoal de ambas as companhias substituísse os $e$-mails por contatos pessoais para solução dos problemas nas áreas de qualidade (métodos de análise, resultados, desvios), equipamentos (compra de itens da planta de Cotia) e PCP (programação, entrega de matéria-prima, embarques de produto acabado).

- O encontro do know-how e das tecnologias de Alffa e Betta permitiu ao corpo técnico de ambas as companhias vislumbrar uma série de possíveis melhoramentos nos
- A Alffa iniciou a análise de eventuais parceiros para o repasse das resinas de fricção (fase de decisão) antes mesmo que o encerramento das atividades na Planta de Cotia estivesse definitivamente decidido (fase de motivação);

- As pesquisas de laboratório, os lotes-piloto e os lotes experimentais com formulações do cliente (fase de implementação) foram iniciados na Betta antes que o contrato estivesse plenamente definido e assinado (fase de decisão). 
Pode-se considerar que o modelo de divisão do processo de outsourcing em estágios ajudou a enfatizar os principais desafios em cada uma das fases do caso estudado, bem como as habilidades necessárias para enfrentá-los. Os motivos para a iniciativa do repasse detectados neste estudo, tais como aumentar o foco da empresa e reduzir custos operacionais, são encontrados com certa facilidade na literatura existente. Por outro lado, características pouco citadas na literatura, como a cultura das empresas e sua nação de origem, mostraram ser importantes na escolha do fornecedor no estágio da tomada de decisão.

Um consistente suporte de tecnologia de informação também aparece como fator chave para que ambas as companhias consigam adequar os processos de planejamento de produção e suprimento de matérias-primas. Percebeu-se a importância do prévio desenvolvimento de soluções de informática visando evitar problemas de intercâmbio de informações constatados ao longo do estágio de implementação.

\section{Artigo recebido em 20/09/2004 Aprovado para publicação em 29/06/2005}

\section{- Referências Bibliográficas}

APREST - ASSOCIAÇÃO BRASILEIRA DAS EMPRESAS PRESTADORAS DE SERVIÇOS A TERCEIROS. Terceirização na Prática. São Paulo: [s.n.], 1994, 20 p.

BIDAULT, F.; DESPRES, C.; BUTLER, C. New product development and early supplier involvement ESI: the drivers of ESI adoption. In: PRODUCT DEVELOPMENT MANAGEMENT ASSOCIATION INTERNACIONAL CONFERENCE, Orlando, 1996.

BRUECK, F. Make versus Buy: the wrong decision cost. The McKinsey Quarterly. n. 1, p. $29-47,1995$.

CALVI, R.; LE DAIN, M.; HARBI, S. BONOTTO, V.M. How to manage early supplier involvement (ESI) into the new product development process (NPDP): several lessons from a French study. In: THE $10^{\mathrm{TH}}$ INTERNATIONAL ANNUAL IPSERA CONFERENCE, Jönköping, 2001.
COLLINS, R.; BECHLER, K.; PIRES, S. R.I. Outsourcing in the automotive industry: from JIT to modular consortia. European Management Journal, London, v. 15, n. 5, p. 498 508 , oct. 1997.

DEKKERS, R. Decisions models for outsourcing and core competencies in manufacturing. International Journal of Production Research, Leicestershire, 38 , n. 17, p. 40854096, nov. 2000.

EHIE; IKE C. Determinants of success in manufacturing outsourcing decisions: a survey study. Production and Inventory Management Journal, p. 31-38, jan. 2001

FLAVIN, J. Who's pulling your chain? AIAG-Action Line. Aug. 2002. Disponível em: <http:// www.aiag.org/ actionline/articles/ aug02.html>. Acesso em: 10 nov. 2002.
FÜRST, K.; SCHMIDT, T. Turbulent markets need flexible supply chain communication. Production Planning \& Control, London, v. 12, n. 5, p. 525-533, jul. 2001.

HARBSON, J.R.; PARKER, PEKAR Jr, P. Smart alliances: a practical guide to repeated success. Hoboken: JosseyBass Publishers, 1998. $167 \mathrm{p}$.

HILL, T. Manufacturing strategy: the strategic management of the manufacturing funcion. Basingsotke: Macmillan, 1993. $337 \mathrm{p}$.

MONCZKA, R.M. Purchasing and supply chain management. Cincinatti: South Western College Publishing, 1998. $672 \mathrm{p}$.
PIRES, S.I. Gestão da cadeia de suprimentos e o modelo de consórcio modular. Revista de AdministraçãoRAUSP, São Paulo, v. 33, n. 3, jul./ set. 1998 .

QUINN, J.B.; HILMER, F.G. Strategic outsourcing. Sloan Management Review, Cambridge, v. 35, n. 4, p. 221232, Summer, 1994

ROTHERY, B.; ROBERTSON, I. The truth about ousourcing. Aldershot: Gower, 1995. 256 p.

WALLER, M.; JOHNSON, M.E.; DAVIS T. Vendor-managed inventory in the retail supply chain. Journal of Business Logistics, 2001. Disponível em: $<$ ht t p ://www.ed m 1 . com/ vmi_retail_sc.pdf $>$. Acesso em: 14/ nov/2002.

- Sobre os autores

Hercules B. Vernalha, MSc

Professor na FAAT- Faculdades Atibaia

E-mail: hbvernalha@uol.com.br

Sílvio R. I. Pires, Dr.

Professor do PPGEP-UNIMEP

E-mail: sripires@unimep.br

Endereço: Rod. Santa Bárbara - Iracemápolis, Km 1 - Santa Bárbara do Oeste - SP - CEP 13450-000

Tel.: (19) 3124-1822/23 - Fax: (19) 3455-1361 